\title{
Oil prices, emission permits trade of carbon, and the dependence between their quantiles
}

\author{
Baoshuai Zhang, Yuqin Zhou*, \\ School of Economics \& Management, Chongqing Normal University, \\ Chongqing, 401331 \\ China
}

Received: May 20, 2021. Revised: November 15, 2021. Accepted: January 2, 2022. Published: January 3, 2022.

\begin{abstract}
The relations between carbon and oil market is concerned by many scholars but little research has focused on the dependence between their quantiles. We use Quantile on Quantile Regression method to study the impact of WTI crude oil price and Daqing crude oil price on carbon price and use wavelet analysis to clean and decompose the time series. Results show that the impact of crude oil on carbon is heterogeneous. Research based on the original sequence shows that crude oil price has a positive impact on carbon price at all quantile levels. Research based on decomposition sequence shows that the positive impact of crude oil on carbon begins to weaken, the zero effect begins to increase, and the negative impact also begins to appear. However, the negative impact on carbon price becomes stronger with the stability of the time series data obtained from the decomposition of crude oil price series gradually improving, while the positive impact gradually weakens.
\end{abstract}

Keywords-Crude Price, Carbon Price, Wavelet Analysis, Quantile on Quantile Regression.

\section{INTRODUCTION}

$\mathrm{E}$ NERGY conservation and emission reduction is the only way for human society to achieve sustainable development. China's energy grows rapidly with huge demand. However, energy security issues are becoming increasing prominent due to restrictions on access to energy resources. At the same time, environmental pollution and greenhouse gas emissions caused by energy using are becoming increasingly serious. These two problems are intertwined to make the China's future energy development have great uncertainty. Carbon emission trading is the most cost-effective method of energy conservation and emission reduction by using the market mechanism $[1,2]$.

With the gradual establishment and improvement carbon market, the influence of various related markets on the carbon market becomes more and more prominent and complex. The futures market for energy products, the stock market for energy companies and the carbon market are closely related to each other. Scholars have paid much attention and have studied much about energy market and carbon market spillover effects [3]. Even most of scholars believe that traditional energy prices are the main driver of carbon prices. As an emerging market, to study the spillover effects of carbon and energy markets is beneficial to effectively understand the dynamics of the carbon market and test the impact of carbon emissions trading policies on energy structure optimization. In particular, the spillover effect among markets can effectively study the impact of one market fluctuation on other markets and obtain measurement through correlation analysis.

At the same time, China's carbon market is in the initial stage when it turns from the pilot market to the national market, the research on information transmission of carbon price and energy price in China is almost blank. While parsing the nonlinear relationship between the carbon price and energy price is conducive to better improve the pricing mechanism for carbon emissions and help determine the link of the futures market and the carbon market link way. Therefore, we study the impact of oil price on carbon price using Quantile on Quantile Regression to provide a reference for the government to establish a carbon market risk prevention mechanism through the analysis of the interaction between energy prices and carbon prices.

The remainder of the paper is organized as follows: Section 2 gives a brief literature review on the related studies. Section 3 describes the methodology of quantile cointegration test, discrete wavelet transform and quantile-on-quantile regression. Section 4 shows data description and includes a discussion of the empirical results. Section 5 concludes the study.

\section{LITERATURE REVIEW}

As an unconventional energy market, the carbon market is significantly affected by other traditional markets, such as coal market, oil market and gas market. Therefore, accurate analysis of the driving effects of traditional energy markets on carbon markets can contribute to the understanding of the dynamics of carbon markets. At the same time, since the carbon trading mechanism is to improve the energy structure and reduce carbon emissions, traditional energy markets may also be affected by carbon markets. Thus, the contribution of carbon emissions trading mechanisms to energy restructuring can be 
effectively assessed by studying the impact of carbon markets on traditional energy markets.

In the field of energy research, the study on the correlation between carbon market and commodity market has gradually become a hot issue meanwhile scholars at home and abroad have carried out in-depth research on such problems. There is a long-term equilibrium relationship between energy price and carbon price, with unsymmetric conduction effect [4]. And there's a weak conduction between the two markets but the transmission effect gradually recovered after the financial crisis [5]. And the fluctuation of energy price has significant effect on the fluctuation of EU carbon price without latent phase but carbon prices can not predict energy prices [6]. When studying the relationship between the carbon market and the crude oil market, nonlinear relationships should also be taken into account [7]. From perspective of time-varying relevance, there is a significant time-varying correlation between the EU carbon market and the crude oil market [8]. In terms of volatility spillover effects, energy prices such as electricity price and natural gas price have strong spillover effect on carbon price fluctuation [9]. International oil prices have a spillover effect on carbon price returns. However, due to the variation of EU energy consumption structure and the continuous improvement of carbon trading mechanism, spillover effects tend to decline [10]. Because of differences in data selection time, and model parameter setting, etc., Ji et al. believed that Brent crude oil price had significant dynamic spillover effect on carbon price between 2006 and 2017 [11].

According to the above research, due to the difference in data, time, analytical methods and model parameters, relevant researches have various findings even have the opposite conclusion. For instance, based on some literature, it finds that two markets are positively correlated [12], [13]. However, Hammoudeh et al. deem them negatively correlated [14]. There is more support for the idea of neutrality, that is, there is no linkage mechanisms between the two markets [15]. Meanwhile, for analytical techniques, econometric modelling is the dominant approach to modelling spillover effects on carbon and commodity markets, such as, linear regression, the cointegration method, Granger Causality test, cross correlation analysis, Generalized Autoregressive Conditional Heteroskedasticity (GARCH) model. Recently, some effective methods have also been used to analyze the complex nonlinear relationship between carbon and commodity markets, such as nonlinear autoregressive models and Copula function models [14], [16].

To sum up, most of the existing studies are limited to directly using the existing models abroad to explore the relationship between crude oil market and carbon price, while only a small number of studies involve the spillover effect of crude oil market on related markets. In addition, there are few researches on the deep-seated relationship between crude oil market and carbon price, especially on the transmission mechanism between crude oil market and carbon price. Compared with conventional techniques such as OLS and quantile regression, Quantile on Quantile Regression method can estimate how crude oil price series and its decomposition series affect carbon price at different quantile levels. Quantile on Quantile Regression method can accurately describe the dependency structure between endogenous variables and regression variables. In view of this, considering the financial attributes of the crude oil market, we first use wavelet analysis to denoise and clean the data, and then use Quantile on Quantile Regression model to explore the intensity and direction of the impact of the crude oil market on carbon prices. The research results are expected to provide useful suggestions for market planners and investors.

\section{METHODOLOGY}

\section{A. Quantile Cointegration Test}

The traditional linear cointegration model only reflects the average response of the dependent variable to the independent variable. If we want to know the long-term equilibrium relationship between the dependent variable and the independent variable on more distribution features, the standard cointegration model is not competent since the conditional mean is only a feature of the probability distribution. An improved approach is to examine the relationships between variables at different sub-points. Then, Xiao proposed the Quantile Cointegration Model which decomposed the errors of the cointegration equation into lead-lag term and a pure innovation component [17], [18]. In addition, the model is the extension of cointegration introduced by Engle and Granger, which is considered to be special with as a vector of constants [19]. In this special case:

$Y_{t}=\alpha+\beta^{\prime} Z_{t}+\sum_{j=-k}^{k} \Delta Z_{t-j} \Pi_{j}+u_{t}$

And,

$Q_{Y_{t}}\left(\tau \mid Z_{\mathrm{t}}\right)=\alpha(\tau)+\beta(\tau) Z_{t}+\sum_{j=-k}^{k} \Delta Z_{t-j} \Pi_{j}+F_{u}^{-1}(\tau)$

Xiao deduced stability test of the cointegrating coefficients from the given (2) and took the null hypothesis as $H_{0}: \beta(\tau)=\beta, \forall \tau \in(0,1) \quad$ [17]. We employs test statistic $\sup _{\tau} \ln (\hat{\beta}(\tau)-\beta) \mid$ across all the distribution of quantiles under the null hypothesis. We do 1000 bootstraps to estimate the critical values of test statistic following Xiao [17].

\section{B. Discrete Wavelet Transform}

\section{(1) Wavelet transform}

Wavelets are function that is oscillatory with ability to attenuate to zero rapidly. Wavelet transform refers to band-pass filter to filter signals at different scales. Given $\psi(t) \in L^{2}(R)$ are space for all squared integration functions, Fourier is transformed into $\psi(\omega)$. When $\psi(\omega)$ meet the condition:

$C_{\psi}=\int_{-\infty}^{\infty}\left|\omega^{-1}\right||\psi(\omega)|^{2} d \omega<+\infty$

Then $\psi(t)$ is a wavelet mother function. Of which, $\psi(t)$ should meet $\psi(\omega=0)=0$. That is. And then $\psi(\omega)$ has band pass property. 
A wavelet function is formed by translation and scaling of the wavelet mother function $\psi(t)$, as shown in formula (4):

$$
\psi_{a, b}(t)=|a|^{-1 / 2} \psi\left(\frac{t-b}{a}\right)
$$

$a, b \in R, a \neq 0, \psi_{a, b}(t)$ are sub-wavelets; $a$ is the scale parameter, and $b$ is the time parameter, which reflects the translation of wavelet in time.

Wavelet transform of signal $f(t)$ is defined as:

$$
W_{\psi} f(a, b)=|a|^{-1 / 2} \int_{-\infty}^{\infty} f(t) \psi\left(\frac{t-b}{a}\right) d t
$$

In formula (5), $\psi(t)$ is complex conjugate function of $\psi(t)$. $W_{\psi} f(a, b)$ are wavelet coefficients at different locations and scales. Since the variables $t, a, b$ in formula are continuous, the upper formula (5) is called continuous wavelet transform. As actual financial data are generally discrete, the parameter $a, b$ are discrete in practice, but this discretization is not only for time variable $t$. Discrete form is as follows:

$$
W_{\psi} f(a, b)=|a|^{-1 / 2} \square t \sum_{k=1}^{N} f(k \square t) \psi\left(\frac{k \square t-b}{a}\right)
$$

In formula (6), $\mathrm{N}$ is discrete point, and $\square t$ is sampling interval. $W_{\psi} f(a, b)$ can reflect the characteristics of time parameter $b$ and scale parameter $a$. And when the $a$ is small, it has low resolution in frequency domain, and high resolution in time domain; As the $a$ gets bigger, it has high resolution in frequency domain, and low resolution in time domain. Therefore, wavelet transform can localize time-series time frequency, and analyze the local.

\section{(2) Wavelet decomposition method}

Noise could interfere with effective information that might exist in the data so that it is very important to obtain effective information from the research data purposefully to remove the useless and interfering noise. In the wavelet domain, the corresponding coefficients of the effective signal are very large while noise corresponds to small coefficients. The coefficients corresponding to noise in wavelet domain still satisfy the Gaussian white noise distribution, which can be evaluated by wavelet coefficients or raw signals, to eliminate threshold value of noise in wavelet domain. At present, the common thresholds value includes fixed threshold method, minimax threshold method as well as heuristic method.

After threshold selection method appearing, the threshold function is introduced to filter the wavelet coefficients with noise. At present, we mainly use soft threshold and hard threshold function, which was proposed by Percival and Walden in 2000 [20].

Hard threshold denoising method. When the absolute value of wavelet coefficients is less than the given threshold, it is set as 0; Conversely, it remains the same, i.e.:

$w_{\lambda}= \begin{cases}w & |w| \geq \lambda \\ 0 & |w|<\lambda\end{cases}$
Soft threshold denoising method. When the absolute value of wavelet coefficients is less than a given threshold, it is set as 0 . Conversely, the threshold value is subtracted, i.e.:

$$
w_{\lambda}= \begin{cases}{[\operatorname{sgn}(w)](|w|-\lambda)} & |w| \geq \lambda \\ 0 & |w|<\lambda\end{cases}
$$

Hard threshold function is superior to soft threshold method in mean square error sense, but the signal creates an extra shock, a jump point, unable to smooth the original signal well. The wavelet coefficients obtained by soft threshold function have good continuity to make the overall signal smoother without obvious jump point. However, the signal will be compressed to produce a certain error. Therefore, in practice, it needs ceaseless attempts for selecting better processing method to improve the estimation accuracy.

\section{Quantile on Quantile Regression}

Most literatures use linear regression method to analyze the relationship between two time series. Koenker and Bassett proposed quantile regression framework (QRA) to analyze and model the dynamiccorrelation and degree structure between time series data, which has become one of the most popular econometric tools [21]. Although QRA model can estimate and analyze the heterogeneous relationship between variables at different points of conditional distribution, the main bottleneck faced by QRA framework is that it cannot capture the entire dependency relationship. In order to avoid this QRA's defect, Sim and Zhou proposed quantile-on-quantile (QQ) method [22].

Then, we model the quantile of carbon trading price returns as a function of oil prices returns (and its frequencies) under the QQ model which can provide a complete and clear picture of the dependency relationship. We realize the QQ method by choosing some uncertainty quantiles and by estimating and analyzing the local effect of oil prices uncertainty and its various frequencies on the different quantiles of carbon trading price returns. We can use single equation regression approach proposed by Sim and Zhou and the triangular system of equations proposed by Ma and Koenker to estimate QQ model [22], [23]. In this paper, we choose the single equation regression approach for estimation and analysis because it is also based upon Ma and Koenker [23], [24], [25]. The single equation regression approach can be explained as follows.

The quantile of the carbon trading price returns $\left(r_{t}\right)$ is represented by $\theta$ and oil price is denoted by oil $t_{t}$. Firstly, we model the $\theta$-quantile of Carbon trading price returns function of its past lag $r_{t-1}$, and can be represented as follows:

$r_{t}=\beta^{\theta}\left(o i l_{t}\right)+\alpha^{\theta} r_{t-1}+v_{t}^{\theta}$

$v_{t}^{\theta}$ is the error term having zero $\theta$-quantile. The function $\beta^{\theta}$ (.) is supposed to be unknown since we do not have prior knowledge about the relationship between variables. We examine the association between the $\theta$-quantile of carbon trading price returns and $\tau$-quantile of oil price returns by linearizing the function $\beta^{\theta}$ (.) with first-order Taylor 
expansion of $\beta^{\theta}($.$) around oil$ which is represented as follows:

$$
\beta^{\theta}\left(o i l_{t}\right) \approx \beta^{\theta}\left(o i l^{\tau}\right)+\beta^{\theta^{\prime}}\left(o i l^{\tau}\right)\left(o i l_{t}-o i l^{\tau}\right)
$$

Following Sim and Zhou, $\beta^{\theta}$ and $\beta^{\theta^{\prime}}$ can be redefined as $\beta_{0}(\theta, \tau)$ and $\beta_{1}(\theta, \tau)$ respectively [22]. Equation (10) can be rewritten as follows:

$$
\beta^{\theta}\left(o i l_{t}\right) \approx \beta_{0}(\theta, \tau)+\beta_{1}(\theta, \tau)\left(o i l_{t}-o i l^{\tau}\right)
$$

On substituting Equation (11) into Equation (9), we get:

$r_{t}=\beta_{0}(\theta, \tau)+\beta_{1}(\theta, \tau)\left(o i l_{t}-o i l^{\tau}\right)+\alpha(\theta) r_{t-1}+v_{t}^{\theta}$

In the present paper, we use Gaussian kernel to weight the observations in the neighborhood of the empirical quantile of uncertainty. Further, we estimate the impact various frequencies of oil prices returns, denoted by oil.d1, oil.d2, oil.d3, oil.d4 on carbon trading price returns.

\section{EMPIRICAL ANALYSIS}

\section{A. Data}

We analyse the representative indexes of China's crude oil futures market, international crude oil futures market and the closing price of domestic carbon trading market. Considering the availability of data, because the domestic crude oil futures data are too short, the article chooses Daqing crude oil spot price index instead (doil), the international crude oil market chooses WTI futures index (oil), and the carbon price chooses the representative Guangdong carbon exchange closing price (r). We select their corresponding daily prices to create the continuous price series. According to the availability of data, all data come from the daily closing price from March 14, 2014 to January 17, 2020. In order to avoid the impact of asynchronous transactions, we just choose the dates when all data have records. Eventually, we get a total of 1284 observations for each series. The article data comes from WIND database, and the logarithmic rate of return is defined as: $r_{t}=100 * \log \left(p_{t} / p_{t-1}\right)$. The descriptive statistics of the samples are specifically shown in Table I. According to Jarque-Bera Test, the three sample sequences are all nonnormal distribution and are significant at the $1 \%$ significance level. The existence of sample nonnormality also highlights that there is no linear correlation between the relevant variables. Therefore, it is feasible to use quantile method to estimate the nonlinear correlation between oil price and carbon price.

This paper uses a new method to estimate the influence of different frequencies of crude oil price on carbon price, specifically analyzes the correlation between variables in the wavelet framework, and then decomposes the original income data of crude oil price into four different frequency components by wavelet analysis. Fig. 1 and Fig. 2 show the decomposition sequence of WTI crude oil price and Daqing crude oil price, showing signs of high frequency and increased fluctuation in the short term, but stable in the long term. According to the above descriptive statistics, the variables are not normally distributed, so the quantile-based method can be used for analysis to solve the heavy tail problem.

Table I Descriptive statistics

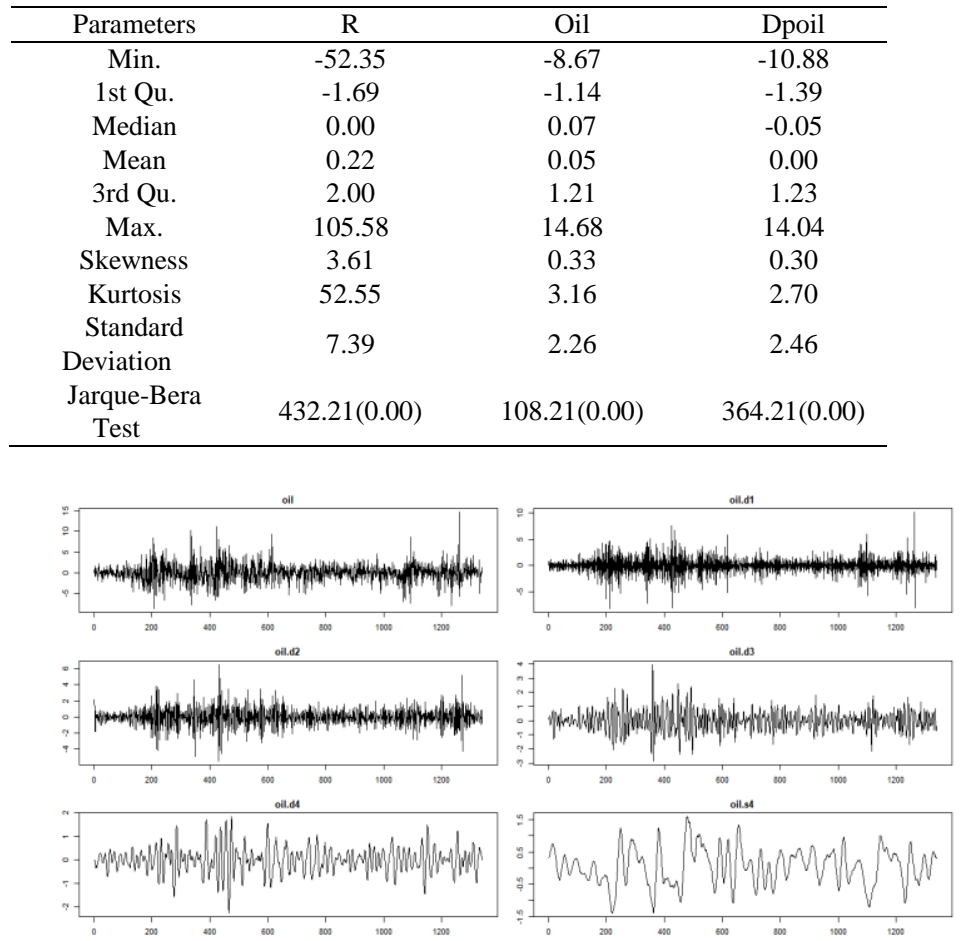

Fig. 1 Trend plot of oil returns
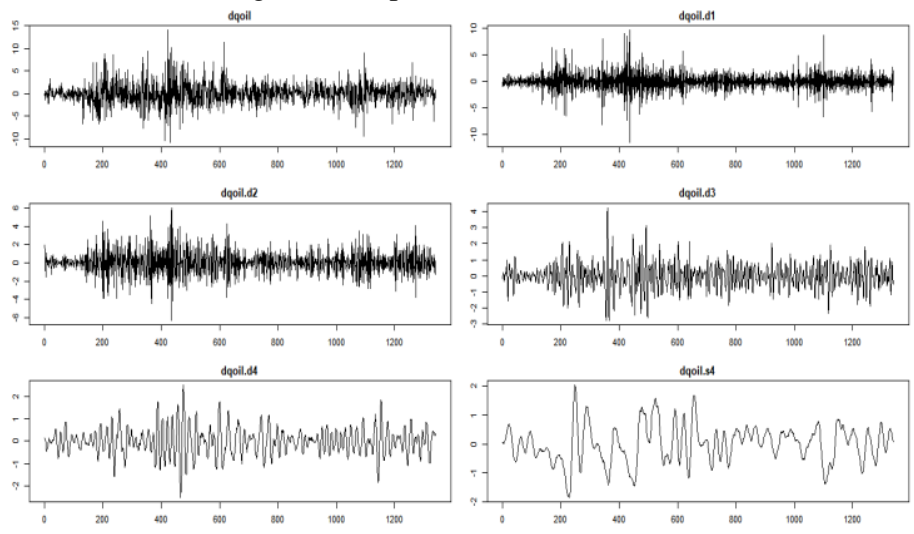

Fig. 2 Trend plot of dqoil returns

\section{B. Quantile Cointegration Test}

The paper uses quantile cointegration method to test whether there is cointegration relationship between variables. In the process of cointegration test, the paper sets variables through a similar interval grid with 19 quantiles (0.05-0.95). The specific estimation results are shown in Table II. There are statistically significant cointegration relationships between carbon price and WTI crude oil price, as well as between carbon price and Daqing crude oil price in China.

Table II Quantile cointegration test results

\begin{tabular}{ccccc}
\hline Model & $\begin{array}{c}\text { Coef } \\
\text { f. }\end{array}$ & $\sup _{\tau}\left|\hat{V}_{\mathrm{n}}(\tau)\right|$ & CV5 & CV10 \\
\hline $\mathrm{r}_{\mathrm{t}}$ vs. oil $t$ & $\beta$ & 1170.62 & $\begin{array}{c}1107.0 \\
11\end{array}$ & $\begin{array}{l}979.1 \\
01\end{array}$ \\
$\mathrm{r}_{\mathrm{t}}$ vs. dqoil $t$ & $\beta$ & 1026.91 & 979.56 & $\begin{array}{c}891.1 \\
9\end{array}$ \\
\hline
\end{tabular}


Note: The CV5, CV10 are the critical values which are produced by using 1000 bootstrap on 5\%, 10\% levels of significance. In addition, we examined cointegration (t-statistic) among the purposed variables by applying 19 quantiles $(0.05-0.95)$ with alike spaced grid.

\section{Quantile on Quantile Estimates}

Fig. 3 and Fig. 4 are the estimation results of applying QQ method to study the influence of crude oil price series and its decomposition series on carbon price. The slope coefficient $\beta(\theta, \tau)$ indicates the influence of the $\tau$-thquantile of crude oil price series and the $\theta$-thquantile of its decomposition series on carbon price under different values of $\theta$ and $\tau$.

Taking the influence of oil on $r$ as an example, according to Fig. 3, in the original sequence, oil has a significant positive influence on $r$ in most quantiles, but the influence degree is very small, and there is a direct connection between oil and r. In fact, oil has a positive and significant effect on $r$ at higher scores, such as 0.85-0.95 levels. In addition, the lower quantile level of oil (0.30-0.50) has a positive and significant effect on the lower quantile level of $r(0.25-0.60)$. Generally speaking, of all the impacts of crude oil prices on carbon prices, oil has a weak impact on r. However, for the extreme tail of the two variables (i.e. low and high quantiles), the positive effect will be enhanced.

Then, we study the influence of decomposition series oil.d1 on carbon price. We can observe that oil.d1 oil price has little influence on carbon price. However, at the lower quantile level of carbon price (0.05-0.35) and the lower quantile level of oil.d1 (0.15-0.45), oil.d1 has a positive and positive impact on carbon price. At the same time, there is also a strong positive impact on the high quantile level of the two, which indicates that there is a decomposed oil.d1 sequence that has a positive impact on carbon prices. We further analyze the impact of decomposition sequence oil.d2 on carbon price: At the lower quantile level, oil.d2 has a positive impact on carbon price, but its intensity is decreasing; at the high score level, oil.d2 has a weak positive impact on carbon price, while the impact at the middle quantile level can be ignored. We also observed a similar situation in the influence of decomposed time series oil.d3 on carbon prices. By analyzing the influence of oil.d1, oil.d2 and oil.d3 decomposition series on carbon price, the study finds that when the crude oil price time series is decomposed, the positive influence of crude oil price on carbon price starts to weaken and the zero effect influence starts to increase. When we further decompose the influence of oil price time series data oil.d4 on carbon price, we observe that the positive effect of oil.d4 gradually weakens while the negative effect begins to increase. The effect of dpoil on $r$ is similar and we will not elaborate here.

At the same time, in order to test the effectiveness of QQ parameter estimation method, we have drawn QQ parameter estimation diagram and QR parameter estimation diagram, as shown in Fig. 5 and Fig. 6. Next, we will still take the influence of oil on R as an example and compare QR and QQ to evaluate the influence of oil on R, as shown in Fig. 5. As can be seen from Fig. 5, there are positive effects at all quantile levels on the original sequence, while on the decomposition sequence, the positive effects of oil prices begin to weaken and the zero effects begin to highlight. The QR method has the same situation. Fig. 5 reveals that QQ line and QR line have the same trend. However, due to the heterogeneity of the impact of the original time series and the decomposed time series of crude oil prices (i.e. Oil.d1, Oil.d2, Oil.d3 and Oil.d4) on carbon prices, Quantile Regression and Quantile on Quantile Regression estimates are somewhat different.

The above analysis reveals the following facts: Although oil price fluctuations may have a positive impact on carbon prices in the short term, with the arrival of stable oil prices, the impact of oil price increases on carbon prices will become more obvious. The results of this study may be attributed to the fact that there are obvious spillover effects in the carbon market and crude oil market, and the rise in global oil prices has a shortterm positive impact on carbon prices.
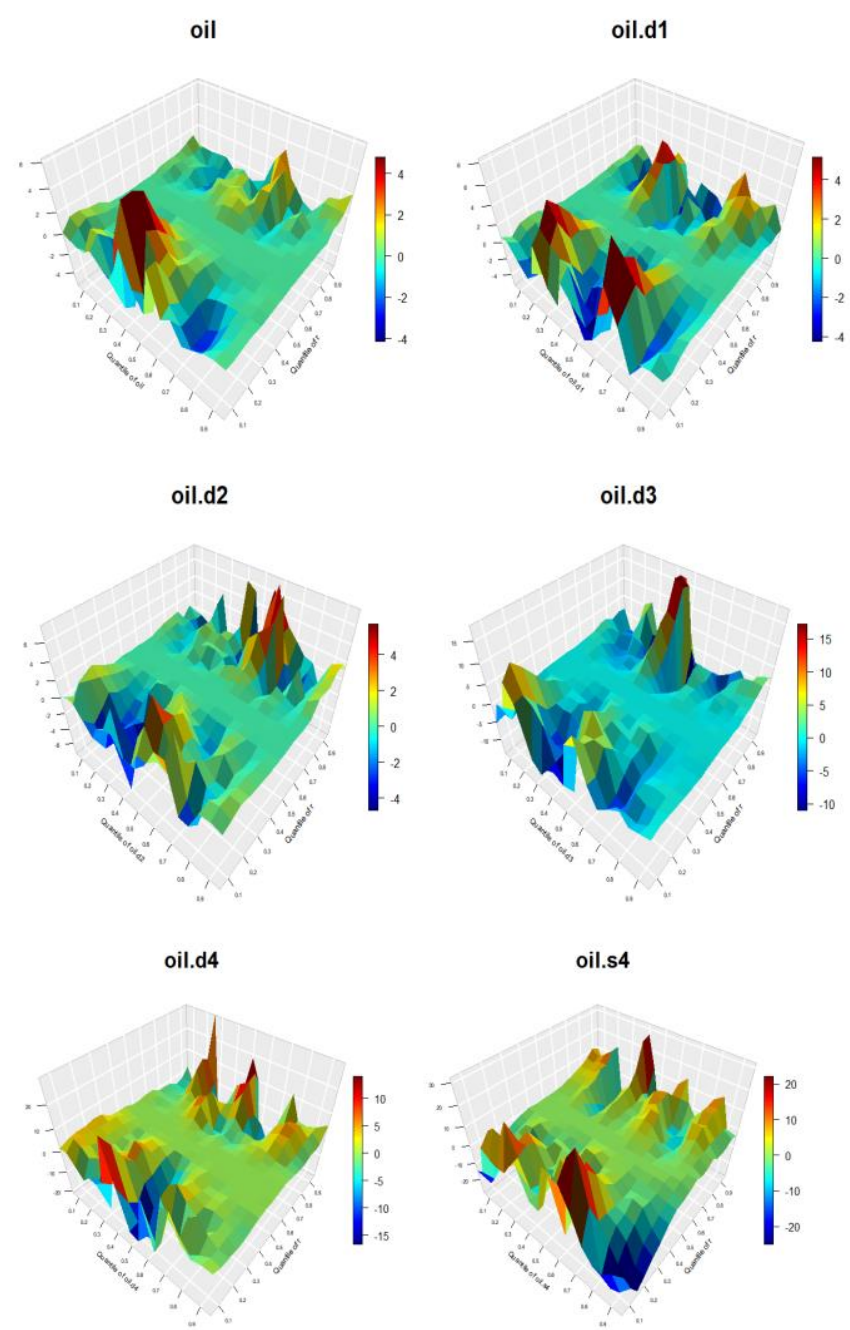

Fig. 3 Quantile-on-Quantile estimates of slope coefficient (impact of oil price on carbon trading price) 

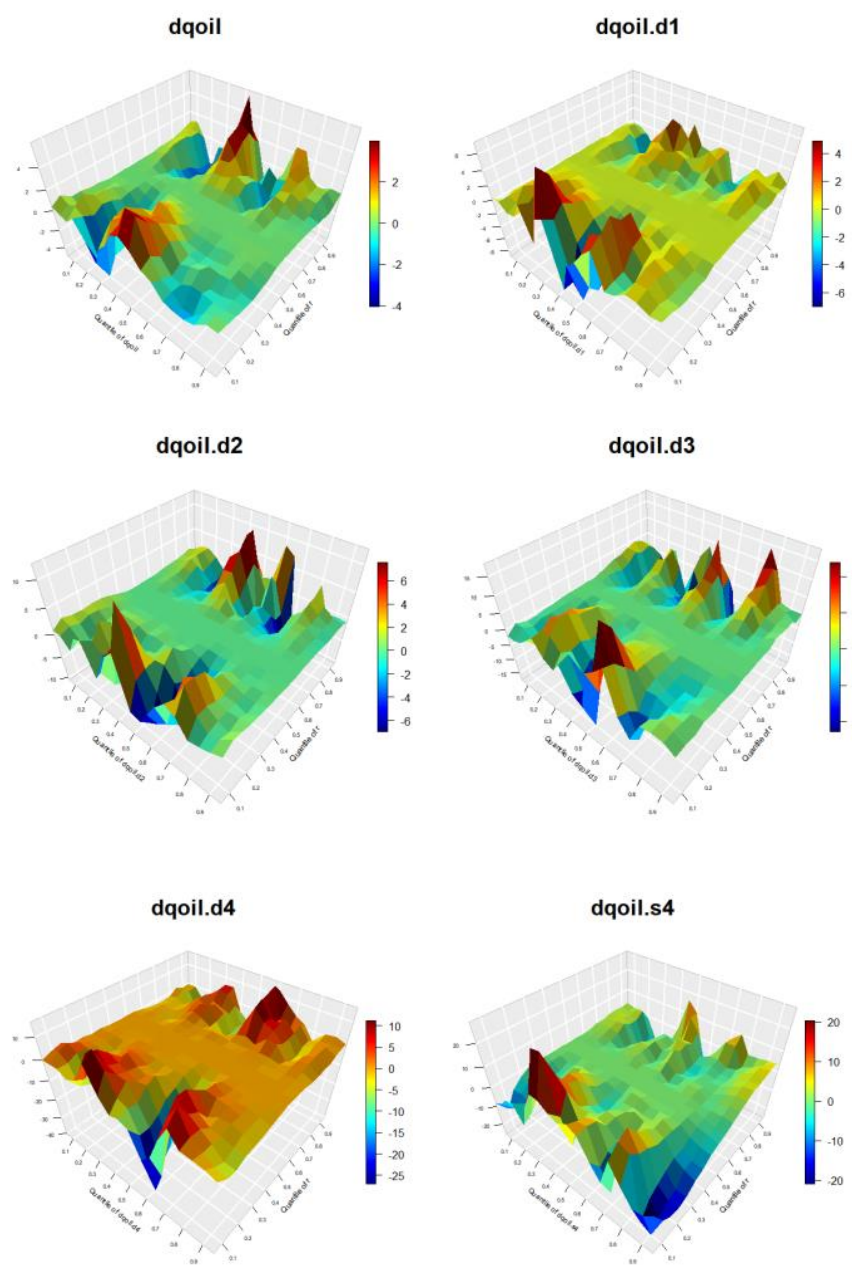

Fig. 4 Quantile-on-Quantile estimates of slope coefficient (impact of dqoil price on carbon trading price)
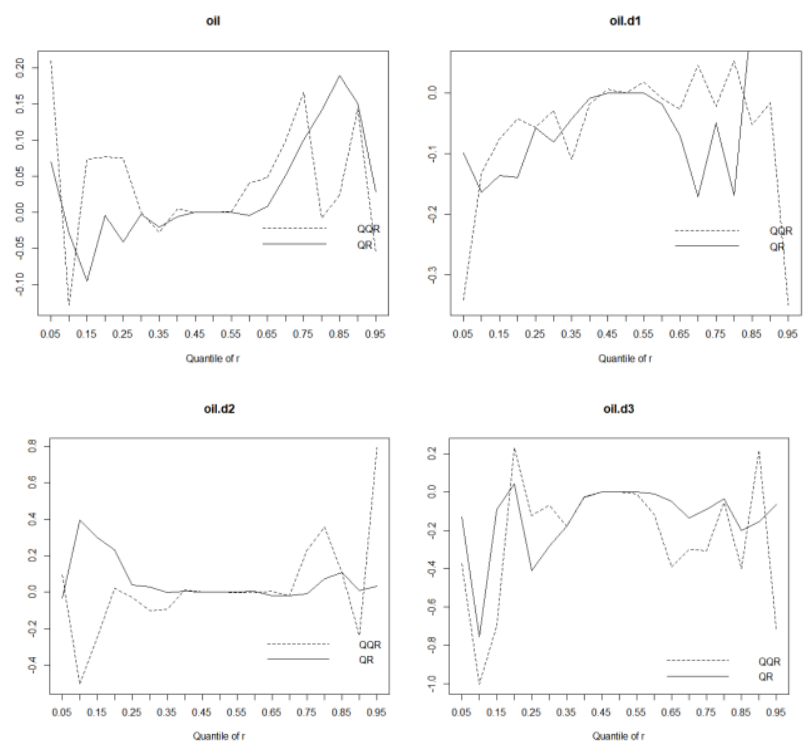
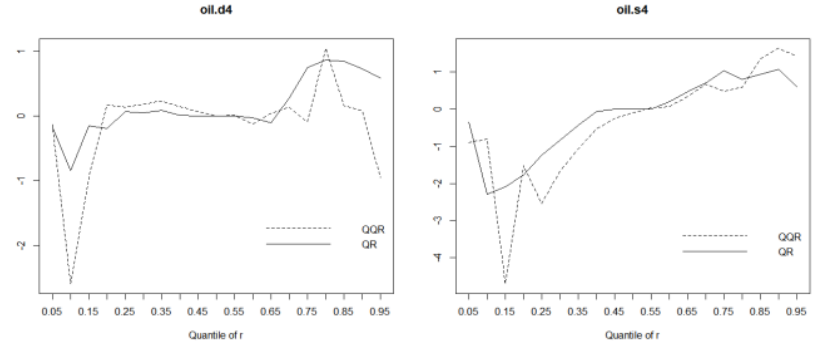

Fig. 5 Comparison between QQ and QR estimates (impact of oil price on carbon trading price)
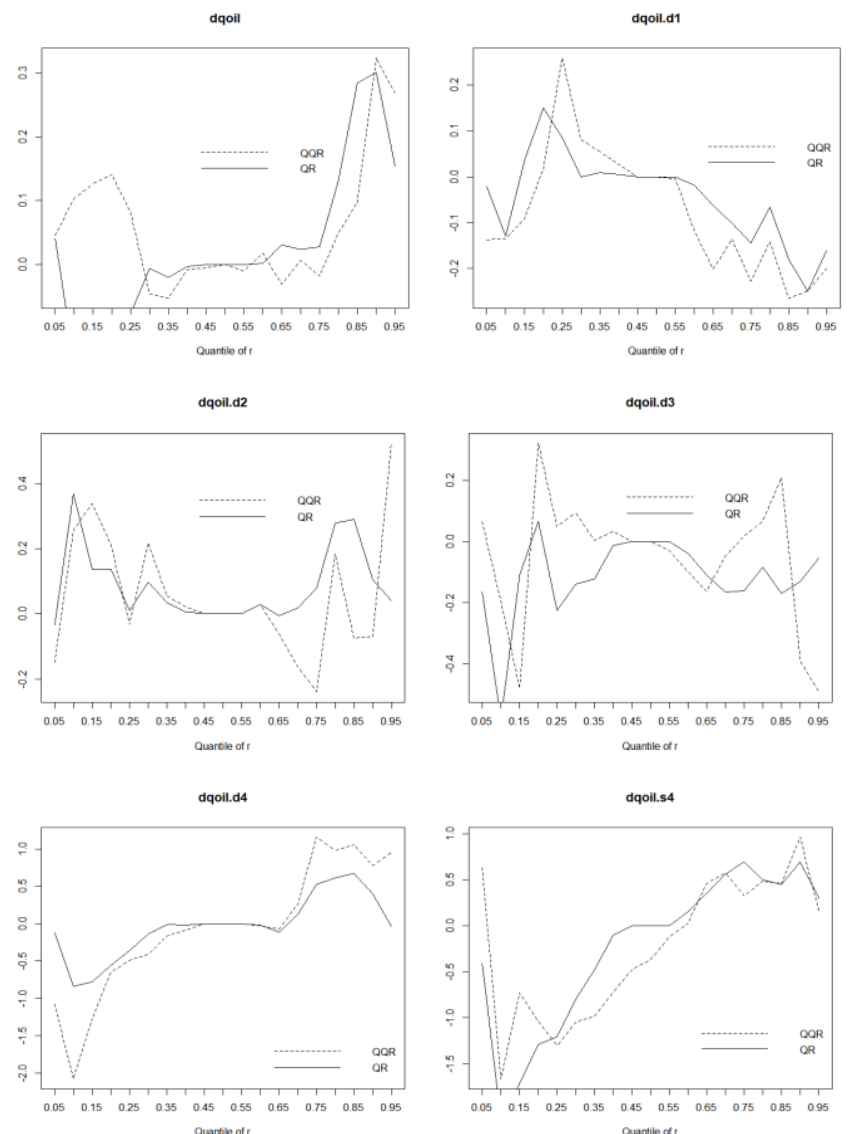

Fig. 6 Comparison between QQ and QR estimates (impact of dqoil price on carbon trading price)

\section{CONCLUSION}

We use daily data from March 14, 2014 to January 17, 2020 to study the impact of WTI crude oil price and Daqing crude oil price on carbon price. First of all, we use wavelet analysis to clean and decompose the time series, and then use Quantile on Quantile Regression method developed by Sim and Zhou to analyze the influence of crude oil price on carbon price [22]. The results show that the impact of crude oil price on carbon price is heterogeneous. Crude oil price has a positive impact on carbon price at all quantile levels based on the research of original sequence. While results based on decomposition sequence show that the positive impact of crude oil price on carbon price begins to weaken, the zero effect begins to increase, and the negative impact also begins to appear. However, the negative and positive impact on carbon price 
becomes stronger and gradually weakens with the stability of the time series data obtained from the decomposition of crude oil price series gradually improving.

The above research results can provide useful suggestions for market planners and investors. The research shows that there are certain deviations in intensity and direction between the original sequence and the decomposition sequence, and there is great heterogeneity in the impact of one market price fluctuation on the other. Therefore, when one market is in turmoil, market planners and investors should consider the linkage mechanism of the two markets at the same time and formulate corresponding plans in time to prevent the turmoil in one market from being transmitted to the other.

We analyze thein fluence of the first moment of crude oil price on carbon price and thus ignore the information related to the high-order moment of the data. Whereas, high-order moment risk of financial market have significant impact on asset pricing and volatility modeling. Therefore, future research could be to investigate the impact of skewness and kurtosis of oil price on carbon price and may be required to further unveil and quantify the impact for a universe of these markets over different time-samples.

\section{ACKNOWLEDGMENT}

Thanks for the Chongqing Social Science Planning Project (No.2018PY74 and No.2018BS57), Science and Technology Project of Chongqing Education Commission (No.KJQN202000506 and No.KJQN201900537). This paper is grateful to the reviewers for helpful comments.

\section{References}

[1] X. Wang, X. B. Zhang and L. Zhu, "Imperfect market, emissions trading scheme, and technology adoption: a case study of an energy-intensive sector," Energ. Econ., vol. 81, pp. 142-158, Jun. 2019.

[2] L. Zhu, X. Wang and D. Zhang, "Identifying strategic traders in china's pilot carbon emissions trading scheme," Energ. J., vol. 41, no. 2, pp. 123-142, 2020.

[3] X. Tan, K. Sirichand, A. Vivian and X. Wang, "How connected is the carbon market to energy and financial markets? A systematic analysis of spillovers and dynamics,' Energ. Econ., vol. 90, pp. 104870, 2020.

[4] Y. M. Wei, L. C. Liu and Y. Fan, "China energy report: Carbon emission research," Science Press, 2008.

[5] W. J. Feng, L. J. Li, W. J. Li, Y. K. Yu and Q. G, "Research on the dependent structure of EU carbon market and energy market-Based on multivariate copula kernel model," Ecological Economy (Academic Edition), vol. 30, pp. 7378, 2014.

[6] S. M. Hosamani, V. B. Awati and R. M. Honmore, "On graphs with equal dominating and c-dominating energy," Appl. Math. Nonlinear Sci, vol. 4, pp. 503-512, 2019.

[7] J. Chevallier, "A model of carbon price interactions with macroeconomic and energy dynamics," Energ. Econ., vol. 33, no. 6, pp. 1295-1312, 2011.

[8] M. Balcilar, R. Demirer, S. Hammoudeh and D. Khuong Nguyen, "Risk spillovers across the energy and carbon markets and hedging strategies for carbon risk," Energ. Econ., vol. 54, pp. 159-172, 2016.

[9] F. J. Convery and L. Redmond, "Market and price developments in the European union emissions trading scheme," Rev. Env. Econ. Policy, vol. 1, pp. 88-111, 2007.

[10] J. L. Wang, "Research on spillover effect of international oil price fluctuation on carbon market," Econ. Research Guide, vol. 5, pp. 70-72, 2012.

[11] Q. Ji, D. Y. Zhang and J. B. Geng, "Information linkage, dynamic spillovers in prices and volatility between the carbon and energy markets," J. Clean. Prod., vol. 198, pp. 972-978, 2018.

[12] M. Mansanet-Bataller, J. Chevallier, M. Hervé-Mignucci and E. Alberola, "EUA and sCERphase II price drivers: Unveiling the reasons for the existence of the EUA-sCER spread," Energy Policy, vol. 39, pp. 1056-1069, 2011.

[13] A. Creti, P. A. Jouvet and V. Mignon, "Carbon price drivers: Phase I versus phase II equilibrium?" Energ. Econ., vol. 34, no. 1, pp. 327-334, 2012.

[14] S. Hammoudeh, A. Lahiani, D. K. Nguyen and R. M. Sousa, "An empirical analysis of energy cost pass-through to $\mathrm{CO}_{2}$ emission prices," Energ. Econ., vol. 49, pp. 149-156, 2015.

[15]J. C. Reboredo. "Volatility spillovers between the oil market and the European union carbon emission market," Econ. Model., vol. 36, pp. 229-234, 2014.

[16] J. C. Reboredo and M. Ugando, "Downside risks in EU carbon and fossil fuel markets," Math. Comput. Simulat., vol. 111, pp. 17-35,2015.

[17] Z. Xiao, "Quantile cointegrating regression," J. Econometrics, vol. 150, no. 2, pp. 248-260, 2009.

[18]P. Saikkonen, "Asymptotically efficient estimation of cointegration regression," Economet. Theor., vol. 7, no. 1, pp. 1-21, 1991.

[19] R. F. Engle and C. W. J. Granger, "Cointegration and error correction: representation, estimation, and testing," J. Econometrics, vol. 55, no. 2, pp. 251-276, 1987.

[20]D. B. Percival and A. T. Walden, "Wavelet methods for time series analysis". Cambridge University Press, 2000.

[21]R. Koenker and G. Bassett, "Regression quantiles," J. Econometrics, vol. 46, pp. 33-50, 1978.

[22] N. Sim and H. Zhou, "Oil prices, US stock return, and the dependence between their quantiles". J. Bank. Financ, vol. 55 , pp. 1-8, 2015

[23] L. Ma and R. Koenker, "Quantile regression methods for recursive structural equation models," J. Econom, vol. 134, pp. 471-506, 2006.

[24] A. Cordero, J. P. Jaiswal and J. R. Torregrosa, "Stability analysis of fourth-order iterative method for finding multiple roots of nonlinear equations," Appl. Math. Nonlinear Sci, vol. 4, pp. 43-56, 2019.

[25] N. Ince and A. Shamilov, "An application of new method to obtain probability density function of solution of stochastic differential equations," Appl. Math. Nonlinear Sci, vol. 1, pp. 337-347, 2020. 
Baoshui Zhang, born in August 1981 in Henan, China, graduated from Zhengzhou University with a bachelor's degree in economics, a master's degree from Chongqing University with a master's degree in economics, and a doctor's degree from Chongqing University with a doctor's degree in management. In 2007, visited Valparaiso University in the United States for one year, and his main research direction was financial risk management.

He began to work in Chongqing Normal University in 2013, won the vice senior title in 2014, and published a monograph 'BS Zhang, J Duan,' Theoretical and Empirical Research on Extreme Value risk of Financial Market', China Social Science Press, 2020.

\section{Contribution of individual authors to the creation of a scientific article (ghostwriting policy)}

Baoshuai Zhang was responsible for the Introduction and the interpretation of result.

Yuqin Zhou (Corresponding Author) has organized the Section 2 and implemented the Quantile on Quantile Regression method and wavelet analysis in $\mathrm{R}$ software.

\section{Creative Commons Attribution License 4.0 (Attribution 4.0 International, CC BY 4.0)}

This article is published under the terms of the Creative Commons Attribution License 4.0

https://creativecommons.org/licenses/by/4.0/deed.en US 